\title{
La regionalización en un contexto de urbanización regional: desde los desafíos a las propuestas de nuevos criterios de zonificación para el caso chileno ${ }^{1}$
}

\author{
Alfredo Rehren², Arturo Orellana ${ }^{3}$, Federico Arenas $^{4}$ y Rodrigo Hidalgo ${ }^{5}$
}

\begin{abstract}
RESUMEN
Las dinámicas de transformación a escala regional de las ciudades en Latinoamérica en las últimas décadas, representa un desafío importante para la regionalización, conforme el espacio de flujos y dinámicas de intercambio de bienes y servicios, la generación de procesos migratorios rural-urbano y de población flotante entre núcleos urbanos de diferente tamaño compromete de manera determinante las condiciones de desarrollo del territorio no sólo urbano, sino territorial y ambiental. Sobre qué criterios debe sostenerse o modificarse la regionalización, resulta ser un punto de partida importante para emprender transformaciones en materia de gobernabilidad, planificación y gestión para que las regiones tengan real protagonismo en el desarrollo nacional y local. En la siguiente propuesta se pretende establecer un ejercicio teórico con un enfoque espacialmente multivariable, que permita ensamblar nuevos criterios para los procesos de regionalización que se avecinan, en un contexto marcadamente neoliberal. En conclusión, los indicadores que resultan del presente ejercicio, permiten avanzar en una región más competitiva, cohesionada socialmente y ambientalmente sustentable.
\end{abstract}

Palabras clave: Regionalización, regiones urbanas, gobernabilidad regional, urbanización regional, criterios zonificación.

\begin{abstract}
The dynamics of regional transformation of cities in Latin America in the last decades represents an important challenge for regionalization, according to the space of flows and dynamics of exchange of goods and services, the generation of rural-urban and population migratory processes Floating between urban nuclei of different size decisively compromises the development conditions of the territory not only urban, but territorial and environmental. On what criteria regionalization should be sustained or modified, it is an important starting point for undertaking transformations in governance, planning and management so that the regions have a real role in national and local development. In the following proposal it is intended to establish a theoretical exercise with a spatially multivariate approach, which allows to join new criteria for the regionalization processes that are coming in a marked neoliberal context. In conclusion, the indicators that result from this exercise allow us to advance in a competitive, socially cohesive and environmentally sustainable region.
\end{abstract}

Keywords: Regionalization, Urban regions, Regional governance, regional urbanization, zoning criteria.

Este texto se basa en una investigación previa publicada en el artículo "Propuesta de nuevos criterios para redefinir unidades político administrativas regionales en Chile" de Orellana, A.; Arenas,F.; Hidalgo, R. y Aliaga, G. (2007), base de la ponencia del Seminario Internacional Colombia Regional en abril 2011 en Bogotá, que origina este artículo. El trabajo que se presenta es producto del Proyecto Anillos/CONICYT SOC 1106. Artículo recibido el 28 de septiembre de 2016, aceptado el 28 de enero de 2017 y corregido el 27 de julio de 2017. Instituto de Ciencia Política, Pontificia Universidad Católica de Chile (Chile). E-mail: arehren@uc.cl 
El nuevo siglo ha colocado de manifiesto la necesidad de pensar cómo habitar los espacios en un planeta cada vez más urbano. Los efectos producidos por un modelo económico globalizado con un acento fuertemente neoliberal, han permitido que el mercado se constituya en el principal agente transformador del territorio por sobre el accionar del Estado, muy especialmente en Latinoamérica. No resulta casual entonces, corroborar que en menos de medio siglo las capitales y principales ciudades del continente americano hayan sufrido un proceso acelerado de metropolización o de urbanización regional, es decir, una expansión del núcleo central urbano que a modo de una "mancha de aceite" va agregando a su nueva configuración socioterritorial, villorrios, pueblos e incluso ciudades menores que otrora estaban en medio de un entorno y una dinámica rural.

Ciertamente las explicaciones no sólo tienen que ver con los cambios inducidos en la estructura económica-productiva nacional y regional, por la apertura a los mercados internacionales, sino también con la marcada situación de conflicto político interno y de quiebre de los procesos democráticos que, en algunos casos, hasta hoy se mantienen en algunos países. Sin perjuicio de ello, los procesos de migración desde el campo a la ciudad, ya sea para buscar refugio o mejores perspectivas laborales, también resultan ser el fruto de un proceso de contrarreforma agraria alimentado en gran medida por la mayor valoración y rentabilidad de la actividad de procesamiento y de servicios agroindustriales por sobre la actividad primaria silvoagropecuaria con perfil campesino.

Bajo este panorama, las ciudades se han convertido en un objeto de deseo para el capital privado, dado que en la medida que han crecido en población, van consolidando un importante mercado interno para la rentabilizar iniciativas de negocios en el ámbito de los servicios y el comercio. Sin ser esto necesariamente negativo, cabe consignar que como lo señaló Sassen (2008), "el capital es el único animal que no tiene lealtades con el territorio", por lo tanto, no es menester entender que todo proceso de crecimiento urbano y más aún de metropolización impulsado por el crecimiento económico, se haga sin consideraciones en materia de cohesión social y sustentabilidad ambiental, al menos es lo que se deduce de las experiencias en Latinoamérica en los últimos treinta años.

Lo anterior resulta ser consistente si se considera que, frente a los requerimientos urgentes que imponen las necesidades de desarrollo de gran parte de los países latinoamericanos, en virtud de los altos índices de pobreza, indigencia y exclusión social, la agenda política privilegia el corto plazo, lo que redunda en que los gobiernos se afanan en proveer empleo, en general mal pagado, sin seguridad social, temporal y de baja calidad. Así entonces, se produce una suerte de dualización del mercado del trabajo, donde un segmento muy reducido de la población, específicamente, el primer decil, alcanza estándares de vida homologables a cualquier país en desarrollo, mientras que el resto de la población busca sobrevivir en un medio laboral inestable, con incertidumbre sobre el futuro y con una alta movilidad residencial, lo cual junto a un proceso de segregación fractura la convivencia social y hace menos amable la vida en comunidad 6 .

Al mismo tiempo, como señala Beck (1998), se va engendrando la "sociedad del riesgo", donde uno de los aspectos más negativos de los procesos de metropolización resulta ser una ocupación inadecuada del medio físico que redunda en la pérdida de sustentabilidad ambiental. Al aumentar la escala de la urbe de forma acelerada, sin tomar los resguardos normativos y de fiscalización que pro-

Sobre el particular, los trabajos de Bauman $(1998,1999)$ y de Sennet $(1998)$ entregan sólidos fundamentos sobre las consecuencias de la globalización en el mercado laboral. 
tejan aspectos relativos a la contaminación del aire, agua y suelo, no sólo se hipoteca de manera importante la calidad de vida de las nuevas generaciones, sino también se pone en riesgo la salud de la población en la actualidad.

Así entonces, el fenómeno de metropolización o de la urbanización regional configura a escala mundial una nueva dinámica y orden político, social y económico, que expresa efectos más allá de sus fronteras urbanas, dando cuenta de un territorio que no es autocontenido, es decir, incide en los procesos de transformación interurbana y regional más allá de su frontera urbana. Por lo tanto, la necesidad de reponer la importancia del ordenamiento territorial como herramienta base que guíe la acción de la política pública y direccione de mejor modo el actuar del mercado, resulta urgente para configurar regiones urbanas donde la metropolización no nos conduzca por el camino que señala Veltz (1997), en términos de que las metrópolis a escala mundial tienden a parecerse, pero, en su interior, a diferenciarse.

\section{La cuestión regional}

No existe una teoría de la regionalización, como tampoco existe una regionalización óptima. La región existe no sólo por una definición geográfica o económica, sino porque también es una construcción mental, una combinación de racionalidad y emocionalidad como lo han señalado Hilhorst (2000), Pommier (2002) y Boisier (1997 y 1999), entre otros. Esta visión, que supone la adscripción a una interpretación sobre la concepción regionalista sostenida fundamentalmente por sociedades que intentan alcanzar mayores grados de autonomía para defender su identidad, costumbres y lenguas, o incluso en forma más práctica, su propia economía y modelo de desarroIlo, lidian sin tregua con una acción institucional promovida desde el Estado nacional, que busca imponer una dirección top-down al desarrollo regional. De este modo, el éxito de cada región queda subordinado a la competencia con sus pares y la condición de privilegio que este tenga dentro de estrategia competitiva asumida desde el gobierno central. Como señalan Amin y Thrift (1995) las regiones pasaron a ser en las últimas décadas, instancias receptoras de las dinámicas y decisiones provenientes de "la mano visible" del Estado nacional, así como de la "mano invisible del mercado", como supuesta acción equilibradora del desarrollo territorial.

La autarquía regional, posible de concebir en el pasado, se encuentra hoy en conflicto con el surgimiento y posicionamiento de la economía en red y globalizada, ya que está supeditada a las conectividades externas y a las dependencias multi-jerárquicas y multi-escalares para poder funcionar adecuadamente (Amin, 2006). Los intentos de promover políticas de desarrollo bottom-up se hacen extremadamente dificultosos para las regiones, básicamente por tres razones importantes. La primera razón obedece a cuestiones de orden institucional, ya que el debilitamiento del Estado para asumir la conducción del proceso de desarrollo en la casi totalidad de Latinoamérica hace que, en mayor o menor medida, las regiones hayan visto mermadas sus facultades y atribuciones para gobernar, planificar y gestionar su territorio. Una segunda razón radica en que, aún bajo la posibilidad de lograr que se fortalezca la construcción de una estrategia bottom-up, se requiere a escala regional una construcción espacial armónica de intereses y reciprocidades, donde los residentes en los grandes centros urbanos, ciudades intermedias y pequeños poblados, junto a los que habitan y sostienen la ruralidad y el paisaje natural, logren converger en un proyecto de desarrollo común e inclusivo, condición que hoy también presenta un nivel de conflictividad im- 
portante. Y, una tercera razón, se explica por un proceso de externalización cultural y de reconfiguración socioterritorial, lo cual en muchos casos ha significado que en el territorio regional nuevas expresiones ajenas a los intereses de preservación de la identidad y sostenibilidad regional, alcancen posicionamiento económico, político y social que inhiben la opción de democratizar los procesos de participación ciudadana en materia de decisiones de interés público.

Así entonces, la construcción de nuevos espacios regionales como nos propone Brenner (1999), enfatiza la necesidad de entender que las ciudades, regiones y Estados no operan como configuraciones geográficas mutuamente excluyentes o competitivas, sino, en cambio, como formas de organizaciones territoriales interdependientes densamente superpuestas. Los planteamientos que sugieren reenfocar las directrices del desarrollo regional sobre la base de estrategias de innovación, competitividad regional, gobernanza asociativa, desarrollo de clústers, entre otras, requieren previamente responder a interrogantes como las que plantea MacLeod (2001), en torno a las reconsideraciones sobre el nuevo regionalismo en relación a países como los de Latinoamérica. Entre las principales: ¿Cuáles son las implicaciones para la estabilidad política-económica del futuro mundo regional entre la difusión apasionada del conflicto de clases en todos los espacios furiosamente industrializados y urbanizados del sur? ¿Cómo puede la globalización estar seriamente desafiada, o por lo menos domesticada con el fin de prevenir la erosión de la democracia? La reciente experiencia de poco más de una década de la Unión Europea proporciona alguna esperanza de que, más allá de las frustraciones y complejidades que ha significado el camino progresivo hacia la reunificación económica, política y territorial, la existencia de un sistema multiescalar de gobernanza puede permitir la prosperidad económica, la democracia política, el iluminismo cultural y la ecuanimidad política interescalar (Moulaert, 1996; Swyngedouw, 1997), así como una relación interregional colaborativa y no competitiva.

En Latinoamérica hemos asistido en las últimas décadas a un fortalecimiento de las grandes ciudades como nodos de acumulación de capital y de consumo, en gran medida a través de un proceso de debilitamiento del ámbito regional, en contraposición a la consolidación de los grandes centros urbanos como principales protagonistas de la nueva economía. Este fenómeno, si bien aparenta ser un fenómeno más o menos reciente tiene, a juicios de algunos autores como De Mattos (1993), larga data, situando su origen temporal en la postguerra y señalando que al iniciarse el proceso de industrialización sustitutiva, los centros urbanos que contaban con mayores ventajas en términos de dimensión del mercado accesible, disponibilidad de fuerza de trabajo, dotación de infraestructura urbana y de sistemas de comunicaciones y de transporte y, eventualmente, proximidad física del poder político nacional, fueron los que ejercieron mayor atracción para las nuevas actividades productivas y para la población. Claramente, la concentración territorial de la industria y de los servicios en aglomeraciones en persistente expansión, favoreció una intensificación en la concentración económica, estimulando a su vez la concentración territorial, generando una paulatina e inexorable propagación de las relaciones de producción capitalista hacia el medio rural (Singer, 1973), al mismo tiempo que consolidaba la posición dominante de los centros urbanos por sobre la escala regional.

En síntesis, el contexto regional en Latinoamérica supone una realidad engendrada a partir de un proceso que esencialmente se explica por un modelo de desarrollo post-fordista que desde su origen encontró en las grandes ciudades una plataforma de crecimiento económico y de acumulación del capital más fértil para una economía de mercado, siendo la región una dimensión territorial que por su complejidad quedó postergada y subordinada a las estrategias productivas 
y de explotación de recursos naturales, promovidas desde el estado nacional, ajenas a una visión integral y sustentable que permitiera un desarrollo más armónico y equilibrado. Así entonces, la necesidad de enmendar lo obrado, es decir, entender que el desarrollo regional constituye una necesidad a abordar con urgencia, no sólo en resguardo de la vida rural y el paisaje natural, sino porque el proceso de metropolización acelerada que está inserto en la realidad regional, admite una dinámica y una complejidad adicional que afecta y afectará también, a futuro, la calidad de vida en el medio urbano.

\section{El reescalamiento de lo urbano: hacia la urbanización regional}

La globalización ha acrecentado la importancia de las grandes ciudades, las que a partir de su rol como nodos articuladores de la economía global, han experimentado procesos de reescalamiento que suelen denominarse bajo diversos epítomes de procesos-formas espaciales tales como metropolización expandida y fragmentada-región urbana (De Mattos, 2010), metropolización del espacio, megaregiones urbanas (Lencioni, 2015) o metropolización-conglomerados urbano regionales (Moura, 2011), por solo citar nociones desarrolladas para el contexto latinoamericano, en el que los nodos metropolitanos que articulan los espacios urbano-regionales cobran especial importancia, porque para muchos países concentran más de un tercio de la población y del Producto Interno Bruto (PIB), como es el caso de Lima, Santiago, Buenos Aires, Montevideo, Caracas, Asunción, La Paz, Managua, entre otras, mientras que sólo en Ecuador, Colombia, Brasil o México, presentan una situación de mayor desconcentración demográfica, económica y funcional, a pesar que estos dos últimos países tienen las dos metrópolis más pobladas de toda América, Sao Paulo y Ciudad de México respectivamente, con poco más de veinte millones de habitantes cada una.

Es así como cabe recordar lo que señala Choay (2004), cuando se pregunta ¿No ha llegado el momento de admitir, sin sentimentalismos, la desaparición de la ciudad tradicional y preguntarse por sobre la que la ha sustituido, esto es, sobre la naturaleza de la urbanización y la no-ciudad que parece haberse convertido en el destino de las sociedades occidentales avanzadas? Lo que se observa del proceso de configuración de la nueva geografía urbana donde predomina el papel de las metrópolis reconvertidas a regiones urbanas, es que el proceso acelerado de liberalización económica generó una reestructuración productiva y financiera a escala mundial, haciendo de las regiones urbanizadas unidades geográficas fundamentales (Brenner, 2003).

Dichas regiones urbanas, incluso en contextos como el latinoamericano se caracterizan por asumir un rango amplio de escalas que pueden trascender los contextos subnacionales o nacionales, hasta alcanzar dimensiones transnacionales; esta nueva geografía de la urbanización (Soja, 2013), implica una intensificación de los efectos sinérgicos producto del incremento de la interacción social, que suele ser movilizada como capital espacial (Soja, 2013). Lencioni (2015), señala que sus características en cuanto a estructura, forma y funciones son las siguientes: metrópolis coalescentes dispuestas a lo largo de centenas de kilómetros, generalmente de tendencia lineal y con patrones de baja densidad, alta dispersión funcional, polinucleación o policentrismo y un carácter de región o totalidad, que deriva de su alta integración espacial, una intensa movilidad y la complementariedad funcional entre sus fragmentos. 
Así, los espacios regionales han ido sucumbiendo ante estas nuevas geografías urbanas que, como explica Dematteis (1998: 17), para el ámbito europeo:

"desde hace un par de décadas una tendencia que hace que con la periurbanización y la 'ciudad difusa' los modelos de sub-urbanización de tipo latino-mediterráneo y de tipo anglosajón, que durante mucho tiempo han seguido caminos diferentes, tienden ahora a converger en un modelo único común a toda Europa de 'ciudad sin centros' de estructura reticular, cuyos 'nodos' (sistemas urbano singulares) conservan y acentúan su identidad a través de procesos innovadores de competición y colaboración".

Este planteamiento revela una de las características más complejas del fenómeno de la metropolización y la urbanización a escala regional, la cual consiste en que las regiones se ven amenazadas en su identidad al urbanizarse, ya que se impone un modelo global de ciudad que se nutre del territorio, pero buscando ocuparlo y adaptarlo a los propósitos de desarrollo impulsados por la lógica del capital.

Conforme la tendencia dominante con la que se inicia el siglo XXI es un proceso de metropolización generalizado, particularmente en América Latina, se proyecta que sólo en términos demográficos en este tipo de regiones urbanas, se concentrarán casi dos tercios de la población. En consecuencia, urge la proyección de estrategias para frenar de algún modo la tendencia, adoptando un enfoque regional para conciliar en forma equilibrada y armónica los requerimientos de expansión urbana, resguardando al mismo tiempo las áreas de interés silvo-agropecuario y/o de protección del paisaje natural, sobre la base de políticas de ordenamiento territorial que mezclen una adecuada regulación sobre el uso de suelo. En tal sentido, la aproximación desde la escala regional para abordar el proceso de metropolización expandida, resulta coherente desde la perspectiva indicada por De Mattos (2010: 277), cuando señala que "si se acepta que la actual metamorfosis urbana está condicionada estructuralmente por tendencias constitutivas de la nueva dinámica de acumulación y crecimiento, es lógico prever que toda propuesta de transformación urbana que busque impulsar modificaciones radicales en la configuración actual de estas ciudades, deberá contemplar necesariamente una previa alteración de dichas tendencias, $-y$, por lo tanto, de los factores que las determinan-, desde que son ellas las que en última instancia han modelado la transición hacia esta nueva forma urbana".

Para que el enfoque regional pueda equilibrar y armonizar los desafíos de la expansión urbana, se debe adoptar una perspectiva espacial multivariable. Los nuevos escenarios económicos, políticos, sociales y culturales que se presentan en diversas escalas (nivel global, nacional y regional), han ampliado los focos de análisis para estudiar y delimitar regiones, por lo cual, esta perspectiva facilita la comprensión de tales dinámicas. Según Boisier (1999), estas nuevas realidades están dadas por la congregación de dos procesos: apertura externa y apertura interna, el primero de ellos causado por la fuerza de la globalización, mientras que el segundo está dado por las fuerzas de la descentralización. En esta misma línea, Cuervo (2003), argumenta que la identificación de una región debe ajustarse al contexto socioeconómico en el cual se ubica, por lo tanto, la fórmula o contenido atribuido al concepto de región es polisémico, polivalente y multiescalar.

En síntesis, la configuración de regiones a partir de ciertos criterios que induzcan un desarrollo competitivo, cohesionado, social y ambientalmente sustentable, constituye un desafío ineludible para los estados nacionales, particularmente en Latinoamérica, sobretodo porque el proceso de urbanización regional irrumpe agregando una nueva y significativa dinámica y complejidad que, de no ser enfrentada, supondrá grandes dificultades en el plano de la gobernabilidad y gestión urbana territorial. 


\section{El origen de la regionalización en Chile}

La regionalización en Chile tiene un pasado reciente, ya que como configuración política-administrativa se inició recién en la dictadura militar que gobernó el país entre 1973 y 1990, aunque con anterioridad se sugerían ya unas regiones de planificación que pueden ser consideradas la antesala del proceso. En 1974, a través de la CONARA7, se llevó a cabo una reorganización de las unidades político-administrativas que buscó la más perfecta materialización posible de la coordinación y la participación de las regiones en función de la Integración, la Seguridad, el Desarrollo Socioeconómico y la Administración Nacional. Es decir, una regionalización anclada en un modelo centralista en lo político y descentralizado parcialmente en lo administrativo, fiel a la doctrina de un estado unitario y centralizado.

El resultado fue la conformación de trece regiones en el país, que quedaron bajo una institucionalidad cuya máxima autoridad es la figura del Intendente Regional, el que es designado por el Presidente de la República para representarlo en el territorio, condición que se mantiene hasta ahora ${ }^{8}$. De regreso a la democracia, se impulsó la denominada Ley Orgánica Constitucional de Gobierno y Administración Regional (LOGCAR), que permitió en el año 1993 dar forma a un Consejo Regional (CORE), cuyos integrantes eran elegidos de manera indirecta, esto es, por los concejales elegidos por votación directa, agrupados por provincia. El emergente gobierno regional estaba así conformado por dicho consejo y por el Intendente Regional, quien además de representar al presidente de la República, es el ejecutivo del Gobierno Regional y hasta hace unos años, presidía el CORE.

Luego, en la pasada década se crearon dos nuevas regiones, las que obedecieron fundamentalmente a viejas reivindicaciones inducidas desde ciudades que vieron mermado su desarrollo a partir de la regionalización de 1974, Arica en el norte del país, que era parte de la Región de Tarapacá y Valdivia, en el sur, que era parte de la Región de Los Lagos, las que habían sido importantes capitales provinciales de dos de las veinticinco provincias que configuraban el modelo de descentralización supra-municipal de estado chileno, hasta la reforma de 1974. Estas dos capitales provinciales habían perdido protagonismo, experimentando un menor desarrollo económico y social en comparación a las ciudades de lquique y Puerto Montt las que, elevadas a la calidad de capital regional, terminan en una posición de mayor primacía urbana.

En el marco de una investigación realizada por Arenas et al. (2007), se pudo advertir que el proceso de configuración de las regiones en Chile, emprendido durante la dictadura militar, no respondió en forma coherente y decidida a ninguno de los criterios clásicos, ni a alguna adecuación o combinación de estos, conforme a lo que se advierte en los procesos de configuración de regiones en diversas experiencias latinoamericanas y europeas.

Estos criterios pueden clasificarse en seis categorías de base (o de primer orden como los denominan los autores mencionados), y que están presentes en mayor o menor medida en la literatura, a saber:

Comisión Nacional para la Regionalización

Pero que podría cambiar, a partir de la modificación de la Ley Orgánica Constitucional de Gobierno y Administración Regional, que se discute actualmente en el parlamento y que, entre otros puntos, incluye la elección de los Intendentes Regionales y que pasaran a llamarse Gobernadores Regionales. 
- Criterio medio natural: las características físicas y ambientales de un territorio que definen en gran parte la identidad y el ámbito de especialización en que una región desarrollará sus actividades económicas. El sistema de poblamiento y de distribución de los habitantes de una región también se encuentra condicionado por las características físicas del territorio. En este criterio deben ser considerados indicadores relacionados con aspectos físicos que describan las principales características respecto al clima, topografía, hidrografía, definición de cuencas, entre otros; de recursos naturales especialmente los recursos hídricos, mineros, silvo-agropecuarios, y pesqueros; y otros indicadores que den cuenta de la degradación ambiental.

- Criterio demográfico territorial: en este criterio se analizan las características del poblamiento en el espacio por parte de los habitantes de cada región, como también aspectos territoriales relacionados con la superficie correspondiente a cada unidad político-administrativa. Las variables que contempla este criterio tienen relación principalmente con las formas de ocupación por parte de la población y las razones por las que se produce determinada distribución en el espacio. Las migraciones interregionales y urbano-rurales, son parte importante de este criterio puesto que permiten conocer aspectos relativos a la dinámica social y económica de la región. Otras variables que deben ser consideradas en este criterio se relacionan con la densidad de población, estructura etaria y de género, esperanza de vida, expectativas de desarrollo territorial endógeno, entre otros.

- Criterio realidad sociocultural: uno de los aspectos menos considerados en anteriores divisiones político administrativas tiene relación con la identidad y el potencial de desarrollo de capital social dentro de una región. La capacidad de una comunidad de organizarse y luchar por un objetivo común habla de arraigo y de presencia de liderazgos que pueden traducirse en el nacimiento de un sentimiento de identificación con su territorio. Esta identidad territorial es una de las variables más complejas de cuantificar, sin embargo, debe ser parte esencial de futuras delimitaciones ya que permite reconocer regiones evitando el establecimiento de estas en forma identitariamente ciega. Otros aspectos que deben ser analizados por este criterio se relacionan con la cantidad y representatividad de organizaciones sociales, el capital social en términos de masa crítica con enseñanza universitaria como base para el desarrollo regional, la presencia de universidades u otro tipo de instituciones de educación superior, entre otras variables relacionadas con la realidad sociocultural de una región.

- Criterio económico productivo: la base económica-productiva que sustenta la dinámica del emprendimiento y del empleo regional, constituye un factor determinante para establecer el tamaño y la morfología del territorio más adecuado para conformar una región como unidad político-administrativa. La articulación y encadenamiento de las diferentes actividades extractivas, industriales y de servicios, tanto desde el punto de vista de la provisión del capital, la tecnología y la mano de obra son aspectos a considerar en el establecimiento de una región. Desconocer la importancia de este criterio para constituir regiones, en el marco de los procesos y dinámicas inducidos por la globalización y la modernidad, resulta ser una decisión de extremo riesgo en la actualidad.

- Criterio administrativo y servicios públicos: toda región establecida como unidad político-administrativa debe estar en condiciones de proveer y administrar los servicios públicos básicos a la población residente en materia de educación, salud, seguridad pública y justicia, para lo cual debe asegurarse o dotarse de la infraestructura, equipamiento y personal 
necesario para cumplir a cabalidad con estas condicionantes. La carencia o merma significativa en la cobertura y calidad en la prestación de servicios públicos, sean estos provistos por órganos del Estado o con participación de privados, derivado de la falta de activos, equipamiento tecnológico insuficiente y falta de dotación de recursos humanos calificados, puede afectar severamente la legitimidad y consolidación de una nueva región.

- Criterio político electoral: la composición, representación y distribución territorial de la institucionalidad política que gobierna el territorio, constituye un factor determinante en el establecimiento de los límites político-administrativo de una región, en la medida que los intereses de ciertos conglomerados y los equilibrios de poder pueden verse alterados por el establecimiento de nuevas regiones, así como por iniciativas tendientes a aumentar los niveles de descentralización regional por la vía de mayor democracia o por la entrega de mayor autonomía en materia de inversión pública regional. Reconociendo que este criterio está marcado por el predominio de parámetros subjetivos fuertemente sujetos a la coyuntura y a la realidad de cada territorio, en la práctica, reviste suma importancia considerarlo como ha sido en el pasado, pero sobre todo a futuro.

En razón de estos criterios, para el caso chileno y analizando las 15 regiones que conforman la actual estructura político administrativa que media entre la escala nacional y la municipal, no es posible encontrar ni en la decisión anterior que conformó las trece regiones, como tampoco en la que dio origen en la década pasada a la creación de las dos nuevas regiones, una coherencia de criterios que pudiesen dar sentido a la configuración resultante 9 . Para solventar este juicio, vale la pena consignar que la Región Metropolitana de Santiago debiera tener su frontera oeste en el Océano Pacífico, incorporando la ciudad y puerto de San Antonio, ya que no sólo resulta ser la única región mediterránea de Chile, sino que además sólo ocupa el $2 \%$ del territorio nacional, concentrando el $34 \%$ de la población y habiendo tenido en el pasado, como Provincia de Santiago (en las divisiones provinciales de 1863, 1917, 1925, 1927 y 1938, litoral propio, incluyendo la localidad de San Antonio (Sagredo et al., 2016). Todo lo anterior, responde a criterios absolutamente diferente a los seis antes mencionados, ya que básicamente se sustentó en la idea de evitar que la ciudad de Santiago y la Región Metropolitana concentraran en demasía la población y crecimiento económico, ambos objetivos que por cierto no han estado ni cerca de lograrse, porque esta región en poco más de tres décadas aumentó su población a un $40 \%$ y aumentó hasta casi un $50 \%$ su participación en el PIB. El único objetivo cumplido, aunque no declarado, es el que Valparaíso se mantiene como el principal puerto del país, más allá de la importancia del puerto de San Antonio, el que sin dudas como parte de la Región Metropolitana hubiese adquirido esa posición tempranamente.

Otro ejemplo más reciente, es la concesión fundamentalmente a la clase dirigente de la ciudad de Arica de corregir la aparente condición de menoscabo que hizo -a juicio de ellos- que esta ciudad no se desarrollara al favorecer a su vecina Iquique como capital regional, aunque ambas competían por el liderazgo en la otrora Región de Tarapacá, lo que llevó a las autoridades en la primera administración de la Presidenta Bachelet (2006-2010) a la creación de la Región de Arica-Parinacota, fronteriza con Perú y Bolivia. El resultado de esta decisión no pudo ser más inadecuado ya que no sólo se desperdició la posibilidad de crear una región especial en razón de su condición fronteriza sino porque además la comuna de Arica concentra casi un 95\% de la población, hacien-

El caso de la recientemente creada Región de Ñuble, actualmente en plena etapa de instalación, se revisa más adelante. 
do que este municipio tenga una condición de poder político, social y económico sin contrapeso en la nueva región, frente a otras comunas, pueblos y localidades urbanas.

\section{Nuevos criterios de segundo orden para regionalizar}

En consideración a los procesos y los criterios históricos que han marcado la descentralización y el desarrollo regional en Chile, en el trabajo de Arenas et al. (2007), se pudo también constatar la necesidad de establecer nuevos criterios para la configuración de nuevas regiones, sobre dos principios rectores. El primer principio, intenta ligar condiciones intra e inter regionales para establecer regiones, y un segundo principio, recoger la multidimensionalidad de la dinámica y complejidad del territorio regional.

El primer principio hizo explícito el requisito de que los nuevos criterios aportaran a los procesos de establecimiento de regiones considerando los impactos posibles en términos del equilibrio socioterritorial, evitando o minimizando que el resultado conlleve a una supremacía excesiva de un municipio por sobre otros en la nueva región o en la región matriz. En el caso del segundo principio, se pretende que los criterios recojan en su concepción una visión más intersectorial y prospectiva del territorio que se quiere establecer como región, así como de aquel territorio residual de la región original.

Para dar sustento a estos dos principios rectores, hay que advertir que existe un contexto muy distinto del que primó hace tres décadas para definir las regiones en el caso chileno, derivado de una combinación de factores que se pueden sintetizar en un menor peso del Estado-nación, una primacía del concepto de competitividad por sobre el de desarrollo y un discurso ciudadano sobre la participación mucho más activo y anclado en consideraciones de carácter territorial y ambiental. En consideración a estos elementos, la propuesta que se planteó apuntaba a la definición de un conjunto de criterios de segundo orden para el establecimiento de regiones y no para su reconocimiento, conforme al hecho de que existe un total convencimiento a partir del análisis de los procesos históricos que dieron forma a la geografía regional del país, a través de fuentes directas e indirectas, y que no existen argumentos de base que hagan viable cualquier propuesta en esa dirección, en el actual contexto por donde transita el país.

Atendiendo el planteamiento expuesto, dentro de los criterios escogidos para identificar regiones se tomó en consideración las sinergias, conexiones y dinámicas socioterritoriales que pudieran dar pie al establecimiento de regiones, reconfigurar o fusionar regiones impulsadas por el primer proceso. Al mismo tiempo, se pretendió que estos criterios mitiguen posibles efectos en el desarrollo regional de zonas que puedan quedar en situación de menoscabo en el sistema, tanto desde una óptica inter como intra regional.

En cuanto a la propuesta de los nuevos criterios para el establecimiento de regiones, se definieron cuatro criterios que se denominaron criterios de segundo orden, por el hecho de que se reconoce que tienen la capacidad de interpretar satisfactoriamente los dos principios rectores planteados, cuyos alcances ya han sido señalados anteriormente. Estos criterios fueron: sostenibilidad territorial, gobernabilidad regional, capital endógeno y recursos de conectividad, cuyas definiciones son las siguientes: 
- Sostenibilidad territorial: referida a la necesidad de sostener una base territorial suficiente en términos de uso y explotación para potenciar el desarrollo regional en las áreas productivas y la generación de empleo de manera más competitiva a nivel país, en cuanto a dotación y flujos de materias e insumos, sin mermar significativamente esta condición a la región de la cual se escinde un determinado territorio.

- Gobernabilidad regional: lograr garantizar que la nueva región sostenga una autonomía territorial suficiente, configurando un tejido social y una institucionalidad que no conlleve la supremacía política, social y económica de un municipio o actores privados individuales o específicos en forma significativa respecto a otras gobernanzas, ni altere en el mismo sentido la condición de la región matriz.

- Capital endógeno: salvaguardar que la nueva región sostenga una dotación institucional y profesional en el ámbito público, privado y académico suficiente para gestionar su desarrollo regional preferentemente endógeno, como también no merme esta condición en la región de la que se escinde.

- Recursos de conectividad: se debe sostener condiciones de infraestructura, transporte y comunicación, y de equipamiento público de servicios, suficientes para atender las demandas socioterritoriales de la nueva región y no alterar significativamente la de la región de la que se desprende.

Aunque esta propuesta de criterios, recoge a satisfacción la complejidad y dinamismo propio del proceso que conlleva prospectar el desarrollo regional, al menos para las grandes urbes latinoamericanas, combinando criterios de primer orden, se hace necesario sumar un quinto criterio que está aún ausente de muchos proceso políticos y legislativos en América Latina, particularmente en Chile, y que emerge con fuerza en muchas regiones a partir de una población residente desencantada, que reivindica derechos y reclama mayor autonomía para conducir su futuro. Se trata de un criterio que podría denominarse de historicidad territorial, entendido este como el reconocimiento de un conjunto de factores identitarios y funcionales de orden histórico y cultural, que trascienden el modelo de desarrollo económico y social imperante, estableciendo alguna frontera ciertamente subjetiva pero significativa en términos de reconocerse sus residentes como parte integrante de un territorio donde convergen dinámicas propias, de intercambio social, político, cultural y económico y con mayor legitimidad ciudadana.

El Cuadro $N^{\circ} 1$ sintetiza los cinco criterios de segundo orden y su relación con los criterios de primer orden:

\section{Cuadro $\mathrm{N}^{\circ} 1$}

Definición de criterios para una nueva regionalización y su relación con los criterios de base o de primer orden

\begin{tabular}{|l|l|}
\hline Nuevos criterios & \multicolumn{1}{|c|}{ Criterios de base o de primer orden } \\
\hline \multirow{3}{*}{ Historicidad territorial } & $\begin{array}{l}\text { Realidad socio-cultural } \\
\text { Demográfico territorial } \\
\text { Político electoral }\end{array}$ \\
\hline
\end{tabular}


Continuación Cuadro $N^{\circ} 1$

\begin{tabular}{|l|l|}
\hline Nuevos criterios & \multicolumn{1}{c|}{ Criterios de base o de primer orden } \\
\hline Sostenibilidad territorial & $\begin{array}{l}\text { Medio natural } \\
\text { Económico productiva } \\
\text { Realidad socio-cultural }\end{array}$ \\
\hline \multirow{3}{*}{ Gobernabilidad regional } & $\begin{array}{l}\text { Demográfico territorial } \\
\text { Administrativo y de servicios públicos } \\
\text { Político electoral }\end{array}$ \\
\hline Capital endógeno & $\begin{array}{l}\text { Demográfico territorial } \\
\text { Realidad socio-cultural } \\
\end{array}$ \\
& $\begin{array}{l}\text { Económico productivo } \\
\text { Político electoral }\end{array}$ \\
\hline \multirow{2}{*}{ Recursos de conectividad } & Económico productivo \\
& Administrativo y de servicios públicos \\
& Demográfico territorial \\
\hline
\end{tabular}

Fuente: Elaboración propia, 2011.

Estos criterios sostienen atributos suficientes para constituirse en filtros técnico-políticos adecuados para evaluar la consistencia y pertinencia de establecer regiones, independiente de los factores impulsores de la decisión. Adicionalmente, tienen la particularidad que simplifican el método de análisis sobre la viabilidad de la constitución de una región, pero al mismo tiempo logran recoger la complejidad que reviste el contexto socioterritorial, permitiendo integrar criterios de primer orden de modo flexible y focalizado, pero sobre la base de los nuevos paradigmas teóricos sobre las visiones y propuestas de los activos relacionales de Storper (1998), del espesor institucional de Amin y Thrift (1992), del capital social de Putnam (2002), del desarrollo endógeno de Vázquez-Barquero (2000), y de la gobernabilidad y gobernanza de Brenner (2004).

La aplicación de estos nuevos criterios supone la necesidad de determinar un conjunto de indicadores asociados a cada uno de los criterios de primer orden con los que se relacionan, según se muestra en el Cuadro $N^{\circ} 1$. Por tal motivo, resulta necesario y recomendable considerar dos indicadores como máximo para cada uno de estos criterios de base. La selección de estos criterios debe definirse a partir de la visión del desarrollo que genera mayor consenso entre los agentes más representativos y con mayor gobernabilidad en el territorio en cuestión, no siendo apropiado en ningún caso ocupar los mismos indicadores para cualquier proyecto de nueva región.

Se propone también que es poco recomendable establecer una región, si no se sostienen en esta nueva región y en la región residual, condiciones mínimas para estos cinco criterios. Si no se cumplen o sólo se cumplen parcialmente las condiciones mínimas, la pregunta evidente es si tiene sentido establecer una región En este caso, la recomendación es que ello se haga sólo si la decisión va acompañada de un paquete de medidas de políticas públicas que permitan asegurar los mínimos exigidos. De esta forma se trata de evitar desbalances intra o inter regional severos, a través del establecimiento de un conjunto de consideraciones que deben expresarse en ciertos 
indicadores de orden cuantitativo y cualitativo, capaces de dar mayor sustento a la decisión en razón de la naturaleza del territorio de que se trate.

Por último, se debe tomar en cuenta que la clave en parte estará en lograr la posibilidad de un rediseño institucional en las nuevas regiones, mediante el cual se busque redefinir una institucionalidad, según las particularidades de cada unidad territorial, combinando modalidades institucionales flexibles para abordar ejes de desarrollo a escala supra o sub regionales. La Figura $N^{\circ} 1$ sintetiza la dimensión conceptual y operativa del trabajo realizado, destacando los criterios propuestos en los párrafos anteriores. Avanzar hacia regiones competitivas, cohesionadas socialmente y ambientalmente sustentable debe ser el objetivo a alcanzar, en un contexto marcado por un modelo económico neoliberal, que ha transformado las relaciones políticas y sociales desde su instauración; donde las nuevas subjetividades político territoriales han comenzado a cuestionar la democracia, y se han plegado a levantar mecanismos de mejoramiento de la participación en ella; la ciudad se ha convertido en un nicho de renta altamente seductivo para los capitales foráneos; el mercado laboral se ha dualizado y se ha conformado una sociedad del riesgo, que ha conllevado a una (in)sustentabilidad ambiental.

Figura $\mathrm{N}^{\circ} 1$

Síntesis de las relaciones conceptuales y propuestas de criterios para una nueva regionalización

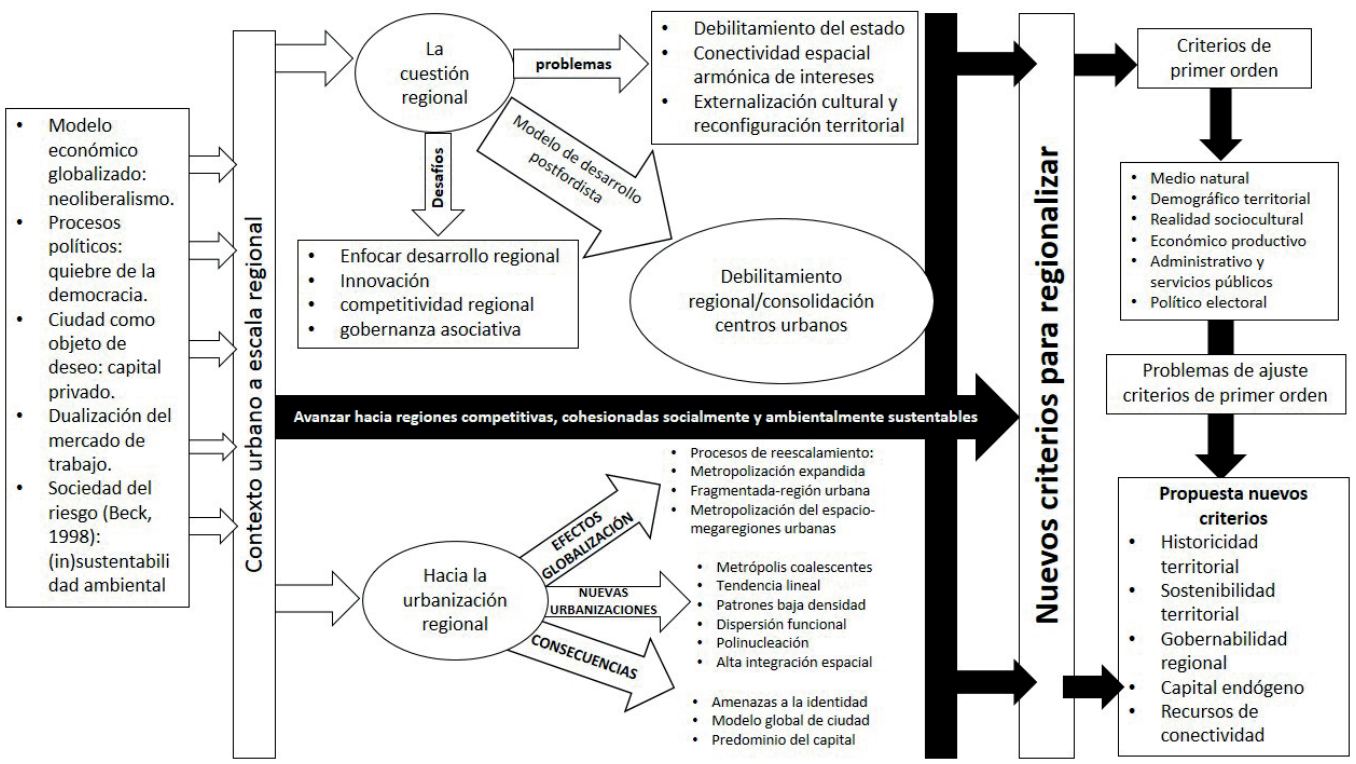

Fuente: elaboración propia basado en la descripción y análisis conceptual realizado.

Como se aprecia en la Figura $\mathrm{N}^{\circ} 1$, los nuevos criterios propuestos para regionalizar pretenden subsanar los problemas de ajustes generados históricamente por los criterios de primer orden. En la actualidad, estos mecanismos no deben obviar medidas que consideren la sustentabilidad como eje de sus acciones y la participación de los actores estratégicos en la formulación de medidas que entreguen soluciones para las inequidades territoriales, concedan mayor poder (a nivel regional y comunal), además de fortalecer y profundizar los procesos democráticos. 
¿Cómo se ha hecho cargo la institucionalidad del nuevo escenario territorial que ha generado este contexto urbano a escala regional? Las acciones se han materializado en la conformación de una Comisión Asesora Presidencial en Descentralización y Desarrollo Regional, que tiene como objetivo establecer diez medidas esenciales para llevar a cabo un desarrollo descentralizado del país, a saber:

a) Definición del Estado de Chile como Estado Descentralizado

b) Elección de la máxima autoridad regional

c) Traspaso de Competencias, servicios y programas

d) Creación de un sistema de administración de Áreas Metropolitanas

e) Ley de Rentas Regionales

f) Fondo de Convergencia para la Equidad Interregional

g) Sistemas Regionales de Gestión de Capital Humano

h) Fortalecer la institucionalidad Pública Regional

i) Democracia Local y Regional

j) Fortalecer la participación ciudadana (Comisión Asesora Presidencial en Descentralización y Desarrollo Regional, 2014).

Estas medidas apuntan a mejorar aspectos que se han generado a partir de un desarrollo político-administrativo que ha tendido a conformar regiones ganadoras y perdedoras. Como se ha señalado anteriormente, la incoherencia en la aplicación de criterios de regionalización ha generado regiones desproporcionadas tanto física como socialmente, como por ejemplo el caso de Arica, donde los argumentos esgrimidos por el poder Ejecutivo para la creación de esta nueva entidad regional, estuvieron relacionados con la existencia de demandas regionales que habían persistido durante más de 30 años (Sánchez, 2009).

Las consecuencias sociales de ello se han traducido en la formación de movimientos sociales regionalistas que han comenzado a exigir la reorganización regional y participativa de los diferentes niveles de la división administrativa del país desde la década de los ochenta hasta el día de hoy (Sabatini, 1993). Por ejemplo, la creación de la nueva Región de Ñuble, viene a materializar las exigencias de un movimiento que se constituye oficialmente hacia 1997, pero que tiene sus raíces en las voces independentistas de la primera protesta regionalista hacia 1983. De acuerdo al estudio realizado por la Universidad de Concepción, "Línea Base, Consideraciones y propuestas técnicas para determinar pertinencia de Creación de Nueva Región de Ñuble" (2013), el 82,2\% de quienes fueron consultados por su inclinación frente a la creación de esta nueva región señalaron su acuerdo en dicho proyecto (Universidad de Concepción, 2013).

¿Se habrán fundamentado los criterios de creación de esta nueva región en indicadores que la hicieran más competitiva, cohesionada socialmente y ambientalmente sustentable? La historicidad territorial se ha manifestado en las exclamaciones de los diversos actores que han incardinado en el cuerpo social la necesidad histórica de separarse de la Región del Biobío. La expresión de los actores involucrados en la toma de decisiones, es un marco de acción que, en fondo y forma, permite la óptima representación de sus intereses hacia el Estado y sus agencias. Esta claridad en los procesos, apunta a equilibrios en la construcción de identidades, con sentido de arraigo y pertenencia. Los recientes casos, como la creación de las regiones de Arica y Parinacota y de Los Ríos, manifiestan una tendencia hacia la distribución espacial del poder no sólo a nivel administrativo-central, sino que también desde una perspectiva de empoderamiento ciudadano 
y participación territorial. Esto también se ha focalizado en la instalación de nuevas comunas, donde la necesidad de especificidad en los instrumentos de ordenamiento territorial y los usos de suelo con fines residenciales, así como el aseguramiento y acceso a servicios básicos como salud y educación, han transitado hacia una demanda creciente hacia el Estado, cuya responsabilidad sobre los equilibrios espaciales, tanto humano-sociales como físico-naturales, es esencial.

No obstante, la sostenibilidad territorial es un aspecto que está al debe. Esto se enmarca en dos vertientes. La primera de ellas está asociada a la sostenibilidad como matriz transversal en la generación de políticas públicas; mientras que la segunda se enmarca en el equilibrio de las relaciones entre el Estado, en tanto ente regulador de los procesos vinculados al ordenamiento territorial y los agentes sociales, quienes representan sus demandas hacia el gobierno central. En ambos casos, la sostenibilidad dialoga como concepto vertebral en la gestión territorial. Los criterios utilizados para el caso de la Región de Ñuble, siguen a aquellos denominados de primer orden, sin sustentar las políticas públicas en la sostenibilidad como principio rector. El fundamento de nuestra propuesta de sostenibilidad descansa sobre el principio de la acción afirmativa. Esta idea tiene como fin equilibrar el acceso a la información y a los mecanismos de participación entre los distintos actores presentes frente a determinadas decisiones. Esta acción de equilibrio tiene como supuesto principal que quienes deliberen en una situación específica tengan, desde un inicio, igualdad de condiciones respecto de la información que manejan; la alternativa de proponer su propia visión; y el derecho a ser considerado como un actor en la producción de políticas públicas. Albert Mosley, filósofo que ha aportado a la discusión de estos temas, se refiere a este principio como "un ideal de justicia reparatoria y participante", considerando que la inclusión es "una forma de compensación para quienes están en desventaja en el acceso a la información" (Mosley, 2005: 46).

La gobernabilidad es un factor determinante en la autonomía e institucionalidad de una entidad regional. La recién creada Región de Ñuble posee una baja cantidad de comunas (21 comunas), lo cual permite una administración adecuada, no obstante, tendrá que sortear la supremacía política e institucional que ejerce la capital de la Región del Biobío. Sostener esta institucionalidad, nos remite a la generación y atracción de un capital endógeno que permita la mantención de todos los asuntos administrativos y políticos. Sin embargo, la nueva región deberá dotarse de una capacidad técnica y profesional robusta, sobre todo considerando que el gran centro de influencia y formación de capital humano se encuentra en Concepción.

Pero, por otro lado, la Región de Ñuble posee una jerarquía del sistema vial que se estructura de manera óptima y que puede ser articulada con nuevas conexiones viales (Universidad de Concepción, 2013). Esto es parte de sus recursos de conectividad, los cuales deben mantener de manera óptima las condiciones de transporte, comunicación y las demandas socioterritoriales de la población. Empero, el nuevo gobierno regional deberá subsanar la falta de pavimento que aún persiste en algunos caminos de la región, y aumentar las conexiones transversales y puentes.

\section{Reflexiones finales}

Considerando que el Estado ha ido perdiendo sistemáticamente mayor peso en los procesos de transformación urbana y territorial, fundamentalmente a escala metropolitana, resulta ser imprescindible que en el afán de poder sostener aún ciertos principios de equidad, eficiencia y sos- 
tenibilidad de la tarea pública, dado que éste se encuentra limitado para poder revertir en forma significativa los desequilibrios al interior de los espacios privados, fruto del modelo de mercado, si lo haga en el ámbito de los espacios públicos. La responsabilidad de proveer de calidad y accesibilidad a espacios públicos a todos los habitantes de una ciudad, sin distinción de condición social, étnica, cultural y/ de otra índole, constituye una tarea de principal urgencia e importancia frente a la realidad latinoamericana actual, siendo este el continente más urbano del mundo.

La propuesta presenta criterios de segundo orden que facilitarán y respaldarán las decisiones futuras sobre la generación de nuevas regiones o la reconfiguración de otras, transitando desde una condición de simples unidades de administración y gestión hacia la constitución de verdaderas plataformas territoriales de poder, más autónomas y con mayor dotación de capital social y de conectividad para asumir el desafío de su desarrollo y de lo que en el caso de Francia denominan colectividades territoriales. En este sentido, cada decisión que apunte a redefinir la geografía política regional, constituirá una respuesta en materia de política pública más acorde al propósito de empoderar la institucionalidad y la población en un territorio para que logre emprender el camino al desarrollo con mayor cohesión social, sustentabilidad ambiental, crecimiento económico y equilibrio territorial.

Dentro de las conclusiones que también entrega el estudio que sustenta este trabajo, está el hecho que resulta imprescindible desencadenar a partir de los elementos contenidos en esta propuesta, una discusión país respecto del para qué se quiere definir una nueva región y qué se espera de ella. Se trata sólo de una nueva unidad político administrativa regional destinada a ser objeto de intervención desde las políticas públicas nacionales de carácter global o sectorial, casi con el único fin de capturar recursos públicos o se espera que mejor definidas, desde el punto de vista funcional y social, ellas se transformen en un espacio de generación de una visión propia acerca de su desarrollo, lógicamente dentro de las definiciones nacionales que le dan coherencia al conjunto de regiones del país, pero con especificidades que ameritan la existencia de una nueva unidad político administrativa.

Adicionalmente, se hace imprescindible tomar en consideración cuatro reflexiones importantes: i) la regionalización exitosa es aquella que surge de un acto político voluntario y legítimo de asociatividad político-administrativa no excluyente en torno a un modelo de desarrollo convergente; ii) las regiones deben tener un proyecto de futuro propio consensuado por agentes sociales, económico y políticos que comparten en el territorio poder para inducir transformaciones urbanas y territoriales de importancia, pero articulado con el proyecto del Estado-nación y en sinergía con los proyectos de otras regiones; iii) la regionalización debe encauzar sus acciones de planificación y gestión sobre la base de una agenda de desafíos acorde con su escala, en conjunto con un acuerdo político-programático para alcanzar otros desafíos vinculantes de escala Interregional y nacional; iv) la regionalización debe construirse dando respuesta al fenómeno metropolitano de facto o en proceso de consolidación, aprovechando sus ventajas y logrando compensar debidamente sus externalidades.

Finalmente, la sola creación de una nueva región no garantiza la generación en un determinado espacio de mayores niveles de desarrollo y de calidad de vida para su población, aunque si se dan las condiciones establecidas en este documento y recogidas por los nuevos criterios aquí planteados, existirá mayor posibilidad de éxito. Del mismo modo, una nueva región que se agre- 
gue al conjunto de regiones del país y que no corresponda al perfil definido en este trabajo, representado por los mencionados nuevos criterios, probablemente al no traducirse en una verdadera colectividad territorial, sólo signifique la generación de un nuevo casillero al que se destine parte de las acciones públicas y recursos, además del natural debilitamiento del sistema de regiones, en cuanto a su peso relativo respecto del Estado nacional.

\section{Referencias bibliográficas}

AMIN, A. La política regional en una economía global. En: FERNÁNDEZ, V.R; AMIN, A. y VIGIL, J.I. (compiladores). Repensando el Desarrollo Regional, Contribuciones globales para una estrategia latinoamericana. Santa Fe: Universidad Nacional del Litoral- Miño \& Dávila, 2008, p. 353-373.

AMIN, A. \& THRIFT, N. Neo-Marshallian nodes in global networks. International Journal of Urban and Regional Research, 1992, N 16, p. 571-587.

AMIN, A. \& THRIFT, N. Institutional issues for the European regions: from markets and plans to socioeconomics and power of associations. Economy and Society, 1995, № 24, p. 41-61.

ARENAS, F.; HIDALGO, R.; ORELLANA, A. y ALIAGA, G. Propuesta de nuevos criterios para redefinir unidades político administrativas regionales en Chile. En: PONTIFICIA UNIVERSIDAD CATÓLICA DE CHILE; SUBDERE; SEGPRES y MIDEPLAN. Camino al Bicentenario, propuestas para Chile. Santiago de Chile: Concurso Políticas Públicas, 2007, p. 349-374.

ARENAS, F. Las estadísticas y el territorio. En: INSTITUTO NACIONAL DE ESTADÍSTICAS (INE). Chile en la tarea de medir las brechas de desigualdad: aspectos conceptuales y de medición. Santiago de Chile: INE, 2005, p.162-168.

BAUMAN, Z. Modernidad líquida. Buenos Aires: Fondo de Cultura Económica, 1999.

BAUMAN, Z. The Globalization. The human consequences. Nueva York: Blackwell Publishers, 1998.

BOSIER, S. El vuelo de una cometa. Una metáfora para una teoría del desarrollo territorial. EURE, 1997, Vol. 23, Nº9, p. 7-29.

BOISIER, S. Teorías y metáforas sobre el desarrollo territorial. Santiago: CEPAL, 1999.

BOISIER, S. Imágenes en el espejo: Aportes a la discusión sobre crecimiento y desarrollo territorial. Santiago de Chile: Editorial Puerto de Palos, 2006.

BRENNER, N. Urban governance and the production of new status spaces in Western Europe 19602000. Review of International Political Economy, 2004, Vol. 11, N³, p. 447-488.

BRENNER, N. La formación de la ciudad global y el re-escalamiento del espacio del Estado en la Europa Occidental Post-fordista. EURE, 2003, N 86, p. 5-35. 
BRENNER, N. Globalization as reterritorialisation: the re-scaling on urban governance in the European Union. Urban Studies, 1999, Nº 36, p. 431-451.

CHOAY, F. El reino de lo urbano y la muerte de la ciudad. En: RAMOS, A.M. (editor). Lo urbano en 20 autores contemporáneos. Barcelona: Ediciones UPC, 2004, p. 61- 72.

COMISIÓN ASESORA PRESIDENCIAL EN DESCENTRALIZACIÓN Y DESARROLLO REGIONAL. Propuesta Política de Estado y Agenda para la Descentralización y el Desarrollo Territorial de Chile. Hacia un país desarrollado y justo. Santiago de Chile: Gobierno de Chile, 2014.

Cuervo, L. Pensar el territorio: los conceptos de ciudad-global y región en sus orígenes y evolución. Santiago de Chile: Serie Gestión Pública, ILPES/CEPAL, 2003, № 40, p. 1- 60.

DE MATTOS, C. Globalización y metamorfosis urbana en América Latina. Quito: OLACCHI-Municipio Metropolitano de Quito, 2010.

DE MATTOS, C. La obstinada marginalidad de las políticas territoriales: el caso latinoamericano. Revista de Estudios Regionales, 1993, N 35, p. 77-114.

DEMATTEIS, G. De las regiones-área a las regiones-red. Formas emergentes de gobernabilidad regional. En: SUBIRATS, J. (editor). Redes, Territorio y Gobierno. Nuevas respuestas globales a los retos de la globalización. Barcelona: Diputación de Barcelona, 2002.

HILHORST, J.G.M. Desarrollo local/regional e industrialización. EURE, 1997, Vol. 23, № 68, p. 7-27.

LENCIONI, S. Metropolizaçao de espaço y a contituiçao de megarregiões. In: FERREIRA, A.; RUA, J. e DE MATTOS, R.C. (organizadores). Desafios da metropolicaç ao do espaço. Rio de Janeiro: Consequência, 2015.

MACLEOD, G. New regionalism reconsidered: Gobalization and the remaking of Political Economic Space. International Journal of Urban Regional Research, 2001, Vol. 25, N 4, p. 804-829.

MOSLEY, A. A Defense of Affirmative Action. In: COHEN, A. \& HEATH, C. (editors). Contemporary debates in applied ethics. Oxford: Blackwell Publishing, 2005, p. 43-58.

MOULAERT, F. Rediscovering spatial inequality in Europe: building blocks for an appropriate 'regulationist' analytical framework. Environment and Planning D: society and Spaces, 1996, № 14 , p. 155-179.

MOURA, R. Arranjos urbano-regionais no Brasil: especificidades e reprodução de padrões. Biblio 3W. Revista Bibliográfica de Geografía y Ciencias Sociales, 2011, Vol. XVI, № 923, Disponible en Internet: http://www.ub.es/geocrit/b3w-923.htm

ORELLANA, A. La gobernabilidad metropolitana desde las periferias: nuevos escenarios para el desarrollo urbano y territorial del Área Metropolitana de Santiago. Holanda: Red ALFA-IBIS/Universidad Técnica de Delft, 2007. 
POMMIER, P. Les systèmes productifs locaux. Paris: Documentation Française, DATAR, 2002.

PUTNAM, R. (editor). Democracies in flux. The evolution social capital in contemporary society. New York: Oxford University Express, 2002.

Sabatini, F. Centralismo y cultura de la dominación. En: Sabatini, F. \& Geisse, G. (editores). La hora de las regiones. Valparaíso: CIPMA, 1993, p.119-123.

Sánchez, R. Las nuevas regiones de Arica y Parinacota y de Los Ríos, Chile. Algunos antecedentes sobre su estructura y funcionamiento. Revista Geográfica Venezolana, 2009, Vol. 50, № 1, p. 87107.

SAGREDO, R.; GONZÁLEZ, J.I. y COMPAN, J. La política en el espacio. Atlas histórico de las divisiones político-administrativas de Chile 1810-1940. Santiago de Chile: Instituto Geográfico Militar - Pontificia Universidad católica de Chile - Instituto de Investigaciones Barros Arana - Dirección de Bibliotecas, Archivos y Museos, 2016.

SENNETT, R. The corrosion of character: The personal consequences of work in the new capitalism. New York: W\&W Norton and Company, 2000.

SINGER, P. Economía política da urbanizacao. São Paulo: Brasiliense, 1973.

SOJA, E. Para além da postmetropolis. Revista UFMG, 2013, Vol. 20, № 1, p. 136-167.

STORPER, M. Las economías regionales como activos relacionales. Ekonomiaz. Revista vasca de economía, 1998, N 41 , p. 10-45.

SWYNGEDOUW, E. Neither global nor local; 'glocalization' and the politics of scale. In: COX, K. (editor). Spaces of globalization: reasserting the power of the local. New York: Güilford, 1997, p. 137-166.

UNIVERSIDAD DE CONCEPCIÓN. Línea Base, Consideraciones y Propuestas Técnicas para Determinar Pertinencia de Creación de Nueva Región de Ñuble. Concepción: Informe, Universidad de Concepción, 2013.

VAZQUEZ-BARQUERO, A. Desarrollo endógeno y globalización. EURE, 2000, Vol. 26, № 79, p. 4765. 
